\title{
Humanity and Environment Co-influence in the Shadow of Technological Convergence
}

\author{
Natalya Ezdina $^{1, *}$ \\ ${ }^{1}$ Plekhanov Russian University of Economics, Department of Political Economy and History of \\ Economic Science, 117997, Moscow, 36 Stremyanny lane, Russia
}

\begin{abstract}
Today one of the most important issues is the search for controlled ways of sustainable development of civilization, society, and a human. Previously, the development of society was determined by natural and evolutionary factors based on the principle of natural selection of living organisms and populations. However, as social institutions are developing, the technological factors of development, determined by the ideas about this phenomenon - the special arrangement of productive forces and the need to protect or change the environment, began to appear. The end of the 20th century was marked by the realization of a new, universal form of economic and technological synthesis - convergence, which, in the process of developing science and improving technology, became so comprehensive and widespread that today it can be called the force that transforms the environment. In this regard, it is convergent technologies that become the focus and the basis for research of the processes uniting the main spheres of human activity - science, society and technology, which will lead to a new form of interaction with the environment, conditioned not only by scientific and technological changes and social factors, but also new organizational forms of their interaction.
\end{abstract}

\section{Introduction}

Convergent technologies arise at the intersection of different technologies, for example bioand nanotechnologies, information and cognitive technologies, etc., which requires interdisciplinary and trans-disciplinary research of the science and technology. For example, for Russian economy if means technological alley between mining, machinery, chemistry, biotechnologies [1-4]. Huge speed of development of the technogenic world, the emergence of global information and communication technologies, a giant network covering the whole world, modify modern spirituality in its various ways. Hypermedia transforms not only the reality itself; it changes the public consciousness, the consciousness of a person, his identity. The expansion of modern technologies forms their risks and dangers, a threat to human and his existence on the earth. But there are also optimistic forecasts of technospheric genesis, promising to improve the environment, the very essence of a human, to create his har-

\footnotetext{
* Corresponding author: ktyf110372@rambler.ru
} 
monious ties with nature. This is the essence of the new directions in science - transhumanism and immortology. In this connection, it becomes necessary to study all the features of this process, to promote its positive results and to counteract the negative. It is necessary to understand the causality of the mutual influence of technologies, their desire to converge not only among themselves, but also with the environment.

In the 21 st century, the basis of all social changes is a science. The instrument of all these changes is technology - scientific, industrial, social, social and cultural. The latter include the actual technologies of influence on people - individually and massively: advocacy of innovations, organizational and self-organizational projects, change of social and individual consciousness and culture. In fact, this is a new kind of social practice aimed at sustainable development.

\section{Materials and Methods}

The meaning and goal of positively oriented social and cultural phenomena is to set such a way of changing social structures in which the processes of the formation of the new - integrative (convergent) and disintegrative (divergent) - go purposefully and in an organized way - from the lowest to the highest levels upward the whole hierarchy.

Therefore the term "convergence" sets a new conception of the new reality of coorganization of society and science, which requires philosophical reflection and analysis. Although the phenomenon of convergence has become widely known due to the so-called NBIC-convergence (nano, bio, info and cognitive technologies) it should be noted that convergence appeared unexpectedly in many areas - in science, technology, and society [5-6]. The idea of universal convergence aroused a wide resonance in society and scientific circles, took upon itself the dominant role of the development of science, technology and the society itself. Convergence has gained a dominant position in the sphere of interaction of technology, science and environment, as well as the whole society as a whole. It also requires new standards of corporative relations [7-8 [ and cross-cultural communications [9].

The rapid development of science-intensive technologies that occurs in the 20th century, or rather in its second half, has created a number of problems for the solution of which it is necessary to actualize the origin of synergies and convergence of not only technologies and knowledge but also the environment of the person's life with its values and ethical imperatives, in relation to the values of sustainable development, which also requires a philosophical understanding and justification. Convergence acquired leadership status in the development of science, technology and the society itself, began to dominate in the processes of their interaction, and this required its inclusion in the field of sustainable development.

The first school of thoughts is represented by the theories of the industrial society (R. Aron [10]), the postindustrial society (D. Bell [11]), the "growth stages" (W. Rostow [12]), who proposed the "optimism" of technological determinism as the most adequate to the spirit of modernity. In the concepts of this direction, modern technologies act as locomotives for techno-social development. It is scientific and technological knowledge in the form of technology that moves the transformation of industrial society into a postindustrial one, and also helps to smooth out ideological, social and economic differences.

The second school of thoughts can be called "pessimistic". It represents the negative impact of a technogenic society on the transformation of modern society and its criticism. This direction was represented, first of all, in the 1960-70s of the XX century in the reports of the Club of Rome (D. Meadows etc. [13]). In their writings it was noted that the domination of technology, not least of information, "leads to the loss of freedom, alienation of the individual, the dehumanization of social relations and, ultimately, the death of civilization."

The third school of thoughts is connected with the works made by M. Castells [14], A. Toffler [15] and others which appeared in the early 1970s. These concepts are suitable for 
the social consequences of revolutions: scientific, technological and informational - soundly and balanced. Such a broader approach allows us to consider scientific and technological development in co-evolution with the development of changes in the environment, generating both positive and negative consequences and problems. Emerging technologies free a person from heavy physical, routine mental work, give hope for improving the functionality of a human being, including his corporeality, ability, way of life. At the same time, these concepts mark the emergence of ecological consequences of the use of new technologies.

The methodology of the convergence concept was further developed in the works of Helga Novotny, a modern sociologist and philosopher. Helga Novotny [16] introduces the concept of an emergent interface. The interface is the basis of interaction, the means of communication of systems among themselves.

The concept of interface has two meanings. The first meaning is the division, the partition, and the second meaning is the interaction of any two systems for information exchange. Its peculiarity consists in the fact that the interface generates completely new effects or properties that are different from the effects or properties of interacting systems. The system suddenly has qualitatively new, emergent properties that are not equal to the sum of the properties of its parts. H. Novotny extended the idea of the interface to the field of knowledge, where different forms and areas of knowledge intersect. Such boundary areas of knowledge can become messengers of future breakthroughs that reduce the level of complexity that can optimize them. This situation of "unexpected meeting" of various fields of knowledge, the emergence of emergent interface, gives impetus to the convergent technological development of society. The concept of "emergent interface" makes a new contribution to the development of the idea of unification, "fabric", intertwining all sorts of activities: scientific and technological. As a result, the concept of the interface and the concept of an innovative, environmentally friendly idea arise within the scientific community.

\section{Results and Discussion}

Convergent technologies are not only a purely technical tool of activity. They should have a broad interpretation such as the attitude of a human being to the environment, which includes the activity and reflexive components, which allows taking into account the ecological component in convergence. Consequently, the NBIC-convergence model is not sufficient to answer the challenge of modern environmental requirements, since it carries a reflexive component that can only be tested with the help of SNBIC-convergence, which includes an environmentally-oriented consciousness of people.

In the era of global crises and changes, the specification of the scientific and technological development of mankind changes which requires re-evaluation and reassessment. There are acute social problems such as the threat of man-made disasters, pollution of the environment, Russia's position in the world, the situation in the sphere of education, energy security, etc., which ecology should study. As its purpose is to embrace the reality from the top, see the depth of dangers and risks, to build a picture of a new reality, as a plan to overcome routine, break stereotypes and anticipate, i.e. preparing and organizing the coming changes. The economics of nature use as modern science possesses cognitive methodological tools that allow not only to comprehend the problems of modern development of society, but also to construct the future, since it immanently exists in the present.

Likely crisis of the global social and economic system, the danger of environmental disasters, the transition to a new technological order requires new tools, algorithms, sustainable development technologies, and a new paradigm not only in science and technology but also in the environment. Rapid progress in the processes of convergence and the development of convergent technologies has become a trend of the times, a prerequisite and dominant of the development of modern society, allowing us to talk about the future unification 
of science, modern technology, society and a man into a single integrated complex. The starting point of our study is the hypothesis of M. Castells "that all the main trends of changes that make up our new, confusing world are correlated, and we can make sense out of their relationship."

The ground of our research was also the placement of a process of revolutionary technological change, such as the emergence of technology convergence, into a context of sustainable development without which it cannot take place and be formed.

Our hypothesis is the following: earlier science as such, including ecology, discovered new phenomena of nature, analyzed them, built on this basis theories, on which then engineers made inventions, created technologies and new models of technology, which, in turn, became the basis of new types of production. And all this happened spontaneously, producing a negative impact on the environment. Today, the question about the integration of all these stages into a single conceptual and organizational system is raised. It will be the basic project of sustainable development, which initially assumes mutual interest and mutual coherence of all these stages, i.e. immediately eliminating occasional useless deviations and related misunderstandings and conflicts, as well as unnecessary costs for unpromising attempts to improve the relationship between a man and nature.

Therefore, on the one hand, convergence appears as a general regulatory mechanism (configurator) of modern development of society. On the other hand, we define a convergent paradigm as an aggregate of technologically and socially acceptable ways and methods of sustainable development of mankind. Representation of convergence as a paradigm has arisen not casually. The unifying tendencies of the scientific and technological development of the society were previously characterized by various paradigms, for example, interdisciplinarily, trans-disciplinarily, integrativity, synthesis. In modern technogenic world, the technological paradigm, built on the convergence of science, technology and society, has become a semantic factor

At the present stage of society development the paradigm of convergence arises as a combination of technological, organizational, ecological innovations. The advantages of this are not only in the production of new products and systems, but most of all - in the dynamics of the regulation of the structure of various systems, as a result of their spontaneous interaction with the obtaining of a new synergistic effect - the accidental emergence of new beneficial results that have arisen on the basis of systemic quality. "The key factor" of this paradigm is not a specific investment of resources - cheap energy or cheap information, derived from the successes of power industry or microelectronics and telecommunications technology, as it was in previous technological paradigms, but collective, intra-system interaction. As a result, a new scientific and technological result is obtained, which inevitably leads to a drop in relative costs and universal availability of production, as well as generating the corresponding social transformations. The difference of the convergence paradigm from the modern technological paradigm lies in the transition from technology based on cheap sources of energy, information, to technology based on a new tool, a new regulator, a new form-maker leading to the unification of systems, with a new result. As such systems, firstly, the technologies that form clusters can be used, by which we mean the unification of several homogeneous elements, which can be regarded as an independent unit with certain properties. And, second, science and technology, forming a new complex - techno-science.

The concept of convergence has a complex structure: it is based on a holistic paradigm (the idea of absolute all-embrace and integrity); the nature of its generality (metaphoricity) is based not on the similarity of objective features, but on the similarity of the structural qualities of systems of any kind - from scientific and theoretical to cultural ones; it has a mirror side - a divergence, which indicates its spontaneously dialectical nature; synergetic based on the mechanism of extrapolation of conclusions and understanding of the nature of 
development as self-organization on the basis of nonlinear and bifurcation processes of the emergence of a new in science, technology and society.

The development of innovative technologies, a new science and their widespread introduction into all fields of human activity, sets before the researchers exclusively new classes of cognitive tasks, for the solution of which it is necessary to comprehend convergent technologies that bring about the convergence and interpenetration of science, technology and a man. The sixth wave of technological development, the beginning of which was expected from 2010, many scientists associate with the development of convergent technologies that interlink, unite and generate new fields of knowledge, at the intersection of such areas as biotechnology, nanotechnology, life design, human change, new nature use, robotics, new medicine, high humanitarian technologies, projecting the future and managing it, etc.

The combination of cognitive, intellectual technologies with information and network ones creates a sphere of convergence - the formation of new social systems that can harmonize the human impact on nature - institutions, laboratories, industries, from politicized groups to parties, etc. - on the basis of free information exchange, the conclusion of contracts and transactions. The general scheme of such a connection is called "SNBICconvergence", and its global use allows us to speak about management of development of all social spheres, social institutions, forms and activities and organization, i.e. society in general and, potentially, the environment.

Prospects for environmentally oriented deployment of SNBIC-convergence are based on such socially significant innovations as nanotechnology (revolution in material production), biotechnology (from genetically modified products to human genotype change), information technologies (from the global Internet to artificial intelligence), and cognitive technologies. These technologies, on the one hand, allow eliminating any obstacles to the spread of convergent ideas, but on the other hand, they give opportunities for abuse of irresponsible individuals and organizations seeking profit or power at any cost (from advertising unproven products to projects of new global wars). This creates a problem of control over processes of technological convergence.

Prospects of social and cultural unfolding of "NBIC-convergences" in the concept of sustainable development concern not only the society, but also the person himself: his body (cyborgization), thoughts (chipping), character (psycho-programming), evolution (unlimited development), his values (unlimited enjoyment - paradise-engineering - immortality); his capabilities (the extropian ideology of unlimited self-perfection of a person's abilities), etc. That is, convergent technologies can become, on the one hand, the engine of sustainable development, on the other hand, a means of transforming a person into a post-human, in the face of technological and cognitive singularity. However, the scale of these ideas is certainly superior to the person's available opportunities - both in the implementation of these ideas, and in anticipation and prevention of possible negative consequences. This creates the problem of a new definition of human nature and the criterion of humanity within the framework of the environmental responsibility ethics.

\section{Conclusion}

Thus, the basis of convergent technologies is post-non-classical cognitive methodology of the formation of new ways of working and thinking tools, the value of which has to be justified specifically and separately from science - in the field of economic growth and sustainable development. The socialization of this practice generates the eco-techno-economy - a combination of technological, organizational, economic and organizational innovations. Its expansion through information and network structures sets a new foundation for sustainable development and a new hierarchy of social structures, the focus of which is nanotechnology - the totality of the newest means of material production. 


\section{References}

1. A.B. Efremenkov, A.A. Khoreshok, S.A. Zhironkin, A.V. Myaskov, IOP Conf. Ser.: Earth Environ. Sci., 50:1, 012009 (2017)

2. S. Zhironkin, M. Gasanov, G. Barysheva, K. Kolotov, O. Zhironkina, E3S Web of Conf., 15, 03012 (2017)

3. A.A. Khoreshok, L.E. Mametyev, A.Y. Borisov, A.V. Vorobyev, IOP Conf. Ser.: Mater. Sci. Eng., 127:1, 012039 (2016)

4. A.A. Khoreshok, P.V. Buyankin, A.V. Vorobiev, A.A. Dronov, IOP Conf. Ser.: Mater. Sci. Eng., 127:1, 012014 (2016)

5. S.A. Zhironkin, K.A. Kolotov, A.E. Genin, F.V. Agafonov, S.A. Kovalevsky, IOP Conf. Ser.: Earth Environ. Sci., 50:1, 012011 (2017)

6. F. Agafonov, A. Genin, O. Kalinina, O. Brel, O. Zhironkina, E3S Web of Conf., 15, 04011 (2017)

7. S.A. Zhironkin,.Ugol', 4, 47-49 (2002)

8. E.V. Kucherova, T.A. Tyuleneva, N.A. Cherepanova, Economics and Innovation Management, 1, 45-51 (2017) DOI: 10.26730/2587-5574-2017-145-51

9. I. Pevneva, O. Gavrishina, A. Rolgayzer, M. Agienko, A. Myaskov, E3S Web of Conf., 15, 04016 (2017)

10. R. Aron, Démocratie et totalitarisme (Calmann-Lévy, Paris, 1965)

11. D. Bell, The coming of post-industrial society. Venture in social forecasting. N.Y.: Collman Pub., 1973. - 884 p.

12. W. Rostow, The Process of Economic Growth (Nation, New York, 1952)

13. D. Meadows, J. Randers, Limits to Growth: The 30-Year Update (Ventura Pub., Los Angeles, 2004)

14. M. Castells et al., Mobile Communication and Society: A Global Perspective (MIT Press, Cambridge MA, 2006)

15. Toffler A. Powershift. Knowledge, Wealth and Violence at the Edge of the 21st Century. - N.Y., 1990. - P.12.

16. H. Novotny, The Cunning of Uncertainty (Polity Press, Cambridge, 2015) 